\title{
Economia, Ideologia e Eleições na América Latina*
}

\author{
Diego Sanches Corrêa
}

Pós-doutorando, Universidade de São Paulo (USP), São Paulo, SP, Brasil. E-mail: diego.correa@usp.br

$\mathrm{N}$ a eleição colombiana de 2006, a proporção de votos do candidato à reeleição Álvaro Uribe foi 8 pontos percentuais superior àquela que lhe garantiu a vitória quatro anos antes. À primeira vista, este resultado pode parecer surpreendente, dado que o desempenho da economia durante o seu governo foi apenas razoável. Nos quatro anos em que governou (2003-2006), a taxa média de crescimento do Produto Interno Bruto (PIB) colombiano foi de $5,2 \%$ e média anual da inflação foi de $5,6 \%$, valores muito próximos às médias de toda a América Latina. Além disto, estudos eleitorais comparados mostram sistematicamente que incumbentes tendem a perder votos de uma eleição a outra (Nannestad e Paldam, 2002). Em contraposição, o candidato do partido governista (Partido Liberal) na eleição presidencial de 1998, Horácio Serpa, obteve uma proporção de votos mais de 10 pontos percentuais inferior à de seu predecessor, o então presidente Ernesto Samper. Economicamente, a atuação do seu governo esteve longe de ser um fiasco, mas o PIB e a inflação tiveram desempenho relativamente pior do que a média da América Latina. É provável que isto tenha contribuído negativamente para as pretensões eleitorais do candidato do Parti-

\footnotetext{
* Agradeço as sugestões e comentários dos professores Rodolfo Hoffmann, Sérgio Praça e Matthew Singer, além dos dois pareceristas anônimos da revista DADOS - Revista de Ciências Sociais. Este artigo foi apresentado nos encontros anuais da Associação Brasileira de Ciência Política e da Australian Political Studies Association de 2014. O projeto de pesquisa que resultou nesta publicação contou com o apoio financeiro da Fundação de Amparo à Pesquisa do Estado de São Paulo (Fapesp).
}

DADOS - Revista de Ciências Sociais, Rio de Janeiro, vol. 58, no-2, 2015, pp. 401 a 425. 


\section{Diego Sanches Corrêa}

do Liberal, que perdeu o segundo turno para o candidato oposicionista Andrés Pastrana. Ainda assim, não é possível explicar a diferença entre os desempenhos eleitorais dos candidatos governistas em 1998 e 2006 com base apenas na performance econômica do governo.

Por que Álvaro Uribe ganhou tantos votos de 2002 para 2006, se o desempenho da economia durante o seu governo foi apenas razoável? Neste artigo, minha resposta é a de que os eleitores colombianos deram um peso menor à economia quando foram às urnas em 2006 do que quando foram em 1998. O perfil ideológico do presidente influencia as expectativas que os eleitores têm de suas ações e pode alterar a natureza da relação de accountability ${ }^{1}$ existente entre eles. Quanto mais longe do centro do espectro ideológico estiver um presidente, menos a economia tende a afetar o voto dos eleitores e o resultado eleitoral. Isto ocorre porque existe uma relação inversa entre extremismo ideológico e programas políticos baseados em questões consensuais, ou valence issues, como crescimento econômico, combate à corrupção, investimentos em saúde e educação etc. Enquanto candidatos centristas tendem a propor agendas de governo que enfatizam questões sobre as quais não há divergências entre a população, candidatos mais à esquerda e à direita tendem a enfatizar suas posições em questões menos consensuais, ou positional issues (Curini, 2015). Consequentemente, os parâmetros que os eleitores utilizam para avaliar se o governo atendeu às suas expectativas variam de acordo com o perfil ideológico do presidente. O sucesso das investidas militares contra guerrilhas comunistas durante o governo de Álvaro Uribe, um direitista, provavelmente o ajudou a se reeleger em 2006, enquanto o fraco desempenho da economia durante o governo de Ernesto Samper, um centrista, deve ter influído negativamente no apoio que seu partido obteve na eleição de 1998.

Este artigo está inserido em uma agenda de pesquisa relativamente antiga, cujo foco tem sido investigar o efeito da economia sobre resultados eleitorais. Evidências da existência deste efeito são apresentadas em inúmeros estudos das mais diversas regiões do planeta, segundo uma recente revisão da literatura (Lewis-Beck e Stegmaier, 2008). Muitos deles identificam fatores que condicionam o impacto da economia sobre as eleições, isto é, fatores que diminuem ou aumentam o grau de accountability pela economia em disputas eleitorais (Anderson, 1995, 2007). Entretanto, quase nenhuma atenção tem sido dada à influência da ideologia do presidente e o principal objetivo deste artigo é preen- 
cher esta lacuna. Meu argumento é que a interpretação do caso colombiano proposta anteriormente é válida para toda a América Latina: apenas governos de centro são punidos ou recompensados eleitoralmente pelo desempenho da economia. O segundo objetivo é mostrar que a hipótese proposta por Powell Jr. e Whitten (1993) de que a economia só afeta resultados eleitorais quando o governo é unipartidário de maioria também é válida para os países presidencialistas latino-americanos, contrariamente aos argumentos de Samuels (2004) e Hellwig e Samuels (2008). Em sistemas presidencialistas, a clareza de responsabilidade pelo desempenho da economia é também diluída quando o governo é de coalizão ou de minoria.

Na próxima seção, discuto o conceito de accountability com base em trabalhos teóricos recentes, atestando a sua importância para a literatura do voto econômico. De fato, virtualmente todos os estudos que buscaram calcular o impacto da economia sobre resultados eleitorais lidam, em algum momento, com as implicações dos seus achados para a natureza das relações de accountability entre eleitores e eleitos em regimes democráticos. Em seguida, apresento o banco de dados e a metodologia que emprego para estimar a influência da ideologia do presidente e da clareza de responsabilidade sobre a capacidade dos eleitores latino-americanos de punir e recompensar candidatos governistas pela performance econômica. Então, exponho e discuto os meus resultados, os quais confirmam que apenas candidatos governistas de centro e governos unipartidários de maioria são eleitoralmente vulneráveis a flutuações da economia. Finalmente, a título de conclusão, avalio a importância desses achados para a literatura do voto econômico e para o modo como se processam as relações de accountability entre eleitores e chefes de governo nos sistemas presidencialistas latino-americanos.

\section{ACCOUNTABILITY, EXPECTATIVAS E CLAREZA DE RESPONSABILIDADE}

O conceito de accountability ocupa uma posição central em teorias da democracia representativa. Cidadãos elegem representantes para atuar em prol de seus interesses no sistema político e esses representantes devem prestar contas aos eleitores no fim do mandato. Partidos de oposição e a mídia desempenham um papel importante, pois também monitoram o governo e informam os cidadãos (Manin, Przeworski e Stokes, 1999). Com base nas informações disponíveis, os eleitores vão às urnas no fim do ciclo eleitoral e dão o veredito sobre a atuação de seus representantes. Eles optam por mantê-los no cargo se 


\section{Diego Sanches Corrêa}

suas expectativas foram satisfeitas ou por dispensá-los se não o foram, utilizando os critérios de avaliação que consideram apropriados. Para que haja accountability, portanto, não basta que os representantes prestem contas sobre seu desempenho ou que fontes alternativas de informação estejam disponíveis aos cidadãos; é necessário que os eleitores detenham a capacidade de sancioná-los (Moreno, Crisp e Shugart, 2003). Eleições livres e competitivas são condições necessárias para a existência deste potencial de sanção eleitoral e, por isto, regimes democráticos são caracterizados por um maior grau de responsividade às demandas da população, em comparação a outros regimes políticos (Dahl, 1973).

O grau de accountability é geralmente tido como importante indicador da qualidade de regimes democráticos, o que, segundo Melo (2007), reflete o viés majoritário da política comparada ${ }^{2}$. Uma quantidade significativa da produção acadêmica tem se dedicado a analisar as condições que afetam esta dimensão da relação existente entre eleitores e representantes, particularmente a capacidade daqueles sancionarem estes. Para meus propósitos, duas considerações são importantes, ambas originalmente formuladas no artigo seminal de Powell Jr. e Whitten (1993). Em primeiro lugar, os parâmetros que os eleitores utilizam para avaliar retrospectivamente o governo variam de acordo com a ideologia do partido no poder. Os eleitores tendem a ver partidos de esquerda como mais competentes para implementar políticas de emprego e os de direita como mais aptos a manter os preços sob controle. Essas expectativas são incorporadas na avaliação do governo pelos eleitores e, desta forma, partidos de esquerda são mais vulneráveis eleitoralmente a variações em índices de desemprego e os de direita a variações em taxas de inflação. O argumento substantivo é que partidos governistas com ideologias distintas são chamados a prestar contas sobre coisas distintas quando concorrem à reeleição e os autores apresentam evidências de países desenvolvidos da Organização para a Cooperação e Desenvolvimento Econômico (OCDE) para sustentá-lo.

Há uma diferença crucial entre os países latino-americanos e os da OCDE, a qual tem implicações para o modo como a ideologia do chefe de governo condiciona o efeito da economia sobre as eleições: aqui, os níveis de desigualdade social são consideravelmente mais altos. Consequentemente, grandes partidos de esquerda tendem a enfatizar com muito mais veemência a redistribuição de renda em seus discursos po- 
líticos, não só através de políticas de emprego, mas também, e principalmente, através de políticas sociais e assistenciais. Analogamente, partidos de direita tendem a enfatizar mais fortemente a manutenção da ordem e a proteção da propriedade privada, sobretudo por meio de políticas de segurança pública. É fácil perceber que avanços nessas agendas políticas não são captados por variações em indicadores econômicos clássicos. A implicação disto para o debate sobre o voto econômico na América Latina é que o desempenho eleitoral de partidos mais próximos aos extremos do espectro ideológico é provavelmente menos suscetível a flutuações daqueles indicadores.

A segunda consideração está relacionada a um debate mais controverso na política comparada. Para que os eleitores sancionem o governo pelo desempenho econômico do país é necessário que eles identifiquem os reais responsáveis por este desempenho. Segundo Powell Jr. e Whitten, em alguns contextos políticos a responsabilidade pela situação econômica é menos clara. Por isto, argumentaram que o efeito da economia sobre o desempenho eleitoral de candidatos governistas é condicionado por uma variável que chamaram de "clareza de responsabilidade". Seu valor é maior em contextos nos quais o partido do chefe de governo não depende de aliados e / ou da cooperação da oposição para governar, isto é, quando o governo é unipartidário e de maioria. Nos outros contextos, a responsabilidade pelo desempenho do governo é difusa e não fica claro quem deve ser responsabilizado pelo sucesso ou fracasso das políticas implementadas. Esta incapacidade do eleitor de sancionar incumbentes por um fraco desempenho econômico seria um indicador de que os laços de accountability entre eles são mais frágeis e, portanto, os achados de Powell Jr. e Whitten (1993) têm implicações normativas importantes.

Uma questão que emergiu nos estudos posteriores é se o argumento da clareza de responsabilidade seria também adequado a sistemas presidencialistas, já que Powell Jr. e Whitten se limitaram a analisar democracias parlamentaristas. Existem diferenças importantes entre as duas formas de governo que poderiam alterar a natureza da relação de accountability existente entre representantes e representados. Em sistemas parlamentaristas, o primeiro-ministro é um agente do Parlamento e é à sua base parlamentar que presta contas durante o mandato. Metade das trocas de governo nesses sistemas ocorre por vias não eleitorais, diminuindo a capacidade dos eleitores de sancionar primeiros-ministros com fraco desempenho (Cheibub e Przeworski, 1999). Em siste- 


\section{Diego Sanches Corrêa}

mas presidencialistas, por outro lado, o chefe de governo é eleito diretamente para um mandato fixo que independe do apoio do Legislativo. Isto fortalece o vínculo entre presidente e eleitores, bem como o grau de accountability existente na relação entre eles. Consequentemente, presidentes seriam eleitoralmente mais vulneráveis a mudanças na conjuntura econômica, mesmo que governando em coalizão com outros partidos e não possuindo maioria na Câmara Legislativa. A hipótese da clareza de responsabilidade, portanto, não se aplicaria a esses sistemas políticos (Hellwig e Samuels, 2008; Samuels, 2004).

Não obstante, ainda que o voto popular estabeleça um vínculo direto entre chefe de governo e eleitores em sistemas presidencialistas, há razões para se acreditar que o contexto político também afeta o grau de accountability nesses sistemas, semelhante ao que ocorre em países parlamentaristas. Em primeiro lugar, é comum que presidentes coloquem a culpa na oposição no Congresso pelas dificuldades enfrentadas durante o mandato. Quando, por exemplo, o orçamento americano não foi aprovado a tempo e o governo fechou as portas por 15 dias no outono de 2013, os cidadãos tenderam a culpar mais a intransigência do Partido Republicano que detinha maioria na Casa dos Representantes do que o presidente democrata Barack Obama ${ }^{3}$. No discurso político, culpar uma oposição que detém maioria na Câmara é uma tática racional e potencialmente persuasiva para se justificar fracassos do governo. Em segundo lugar, quando um governo de coalizão é bem-sucedido economicamente, não há porque duvidar de que os partidos aliados reivindicarão créditos pelo sucesso. Se esta é uma estratégia eficiente, mais uma vez a clareza de responsabilidade pelo desempenho econômico seria diluída. Assim, uma forte associação entre a economia e resultados eleitorais só se verificaria em contextos de governos unipartidários de maioria, como ocorre nos sistemas parlamentaristas investigados por Powell Jr. e Whitten. A segunda hipótese que testo neste artigo é se os achados desses autores também são válidos para as democracias presidencialistas latino-americanas.

\section{DADOS E METODOLOGIA}

As análises apresentadas a seguir buscam estimar o efeito da economia sobre o desempenho eleitoral de candidatos presidenciais governistas, bem como a influência da ideologia do presidente e da clareza de responsabilidade sobre este efeito. Elas se baseiam em um banco de dados com informações para 84 eleições presidenciais que ocorreram em 18 
democracias latino-americanas entre 1990 e $2010^{4}$. Foram incluídos os casos da Argentina, Bolívia, Brasil, Chile, Colômbia, Costa Rica, El Salvador, Equador, Guatemala, Honduras, México, Nicarágua, Panamá, Paraguai, Peru, República Dominicana, Uruguai e Venezuela. O indicador de desempenho eleitoral do candidato governista, que é a variável dependente nos modelos estimados a seguir, é simplesmente a diferença entre a sua proporção de votos na eleição atual e a proporção de votos que o seu predecessor obteve na eleição anterior ${ }^{5}$. O sinal da variável indica se sua proporção de votos aumentou ou diminuiu relativamente à eleição anterior. Note que nem sempre o candidato governista é o atual presidente, já que em todos os países latino-americanos há limites para o número de mandatos presidenciais que uma mesma pessoa pode exercer. Em apenas 16 eleições, ou quase $20 \%$ do total, o atual presidente concorreu à reeleição e uma variável binária indicando esses casos foi incluída nos modelos como controle, pois presidentes possuem vantagens eleitorais em termos de reconhecimento do nome e organização que outros candidatos não possuem (Samuels, 2004). O sinal desta variável de controle, que chamo de "Reeleição", deve ser sempre positivo. Nos demais casos, o candidato à reeleição é aquele que foi explicitamente apoiado pelo partido do candidato que venceu a eleição anterior ${ }^{6}$. Em oito eleições, ou quase $10 \%$ do total, o partido governista não apresentou ou apoiou candidatos, e elas foram excluídas da análise ${ }^{7}$.

As principais variáveis independentes são dois indicadores da conjuntura econômica: o crescimento do PIB e a inflação. Os dados são do World Economic Outlook Database (setembro de 2011) e foram coletados diretamente do site do Fundo Monetário Internacional (FMI). Eles se referem ao ano que precedeu cada uma das eleições incluídas na amostra, independentemente do mês em que ocorreu a eleição ${ }^{8}$. Para reduzir a influência da hiperinflação do início dos anos 1990 nos resultados da análise estatística, utilizo o logaritmo deste indicador. Seguindo a abordagem de Powell Jr. e Whitten (1993), operacionalizei essas variáveis tendo como base de referência o desempenho geral da América Latina. Isto é, para cada caso subtraí o indicador nacional do indicador regional latino-americano, de forma que a variável indica se o país cresceu mais ou menos que, ou teve inflação superior ou inferior à, média observada na América Latina. A intuição é que para avaliar se o país apresentou um bom desempenho econômico em determinado ano, o eleitor compara a performance nacional com a de outros países, em vez de interpretar os indicadores nacionais de forma isolada. Ade- 


\section{Diego Sanches Corrêa}

mais, isto reduz vieses relativos a efeitos de autocorrelação serial: crescer em tempos de prosperidade regional pode ser menos significativo do que crescer em tempos de recessão. As variáveis econômicas operacionalizadas dessa maneira captam, portanto, um importante aspecto do cálculo eleitoral.

A Tabela 1 apresenta resultados de quatro modelos de regressão linear que estimam o impacto da economia sobre o desempenho eleitoral do candidato incumbente. No primeiro modelo foram incluídos os dois indicadores, no segundo apenas o crescimento do PIB, e no terceiro e quarto apenas a inflação. Os modelos controlam pela variável "Reeleição" e pela proporção de votos que o presidente eleito obteve na eleição anterior. Esta última variável foi incluída seguindo o padrão da literatura, já que quanto melhor o desempenho eleitoral de um partido na eleição anterior, maiores são as chances de perda de votos na eleição seguinte. O coeficiente desta variável deve, portanto, ter sempre o sinal negativo. Os modelos 1 e 2 mostram que o crescimento do PIB impactou significativamente no desempenho eleitoral de candidatos incumbentes. Um crescimento superior ao latino-americano em 1 ponto percentual do PIB rendeu a eles cerca de 1,2 ponto percentual de votos válidos na eleição seguinte. Dado que na média das 76 eleições incluídas na análise os candidatos governistas perderam mais de 8,5 pontos percentuais de votos de uma eleição a outra, um bom desempenho econômico no ano anterior ao da eleição poderia protegê-los da natural perda de apoio que chefes de governo tendem a sofrer durante o mandato e garantir-lhes a reeleição.

Tabela 1

Voto Econômico na América Latina

\begin{tabular}{lccccccccc}
\hline & \multicolumn{1}{c}{ Modelo 1 } & Modelo 2 & Modelo 3 & $\begin{array}{c}\text { Modelo 4 } \\
\text { (<1996) }\end{array}$ \\
\cline { 2 - 9 } Variável & $\mathbf{b}$ & $\mathbf{p}$ & $\mathbf{b}$ & $\mathbf{p}$ & $\mathbf{b}$ & $\mathbf{p}$ & $\mathbf{b}$ & $\mathbf{p}$ \\
\hline Crescimento do PIB comparado & 1,18 & 0,01 & 1,22 & 0,01 & & & & \\
Log da inflação comparada & $-0,01$ & 0,82 & & & $-0,03$ & 0,25 & $-0,06$ & 0,07 \\
Reeleição & 0,12 & 0,00 & 0,12 & 0,00 & 0,13 & 0,00 & 0,14 & 0,05 \\
Voto anterior & $-0,36$ & 0,01 & $-0,36$ & 0,01 & $-0,41$ & 0,00 & $-0,56$ & 0,02 \\
Intercepto & 0,04 & 0,49 & 0,04 & 0,49 & 0,07 & 0,29 & 0,07 & 0,51 \\
\hline $\mathrm{N}$ & 76 & & 76 & & 76 & & 22 & \\
$\mathrm{R}^{2}$ ajustado & 0,24 & & 0,25 & & 0,18 & & 0,38 & \\
\hline
\end{tabular}

Fonte: Banco de dados “CCT" (disponível em www.sites.google.com/site/diegosanchescorrea/). 
No entanto, a inflação parece não ter influído significativamente no desempenho eleitoral dos candidatos governistas latino-americanos entre 1990 e 2010. Este achado é consistente com o argumento de Singer (2013), segundo o qual a inflação perdeu relevância como parâmetro de avaliação do governo à medida que os países latino-americanos superaram o período crítico da hiperinflação. Alguns dos autores que realizaram análises similares às apresentadas acima encontraram um forte efeito da inflação (Remmer, 1991, 2003; Echegaray, 2005), mas este efeito tende a diminuir e a perder significância quando eleições a partir de fins dos anos 1990 são consideradas (Singer, 2013). Quando a amostra de eleições é restrita ao período 1990-1995 (modelo 4), o coeficiente para inflação mantém o sinal negativo, dobra de valor e se torna significante ao nível de 0,1 . Isto sugere que os eleitores estavam realmente mais atentos a flutuações deste indicador naquela época do que estão atualmente.

Os resultados apresentados na Tabela 1 confirmam conclusões de outros estudos e indicam que a economia é um importante determinante do desempenho eleitoral de candidatos incumbentes na América Latina. Ainda assim, esses resultados nada dizem sobre a influência de fatores contextuais. Como apontado no início deste artigo, é possível que certos governos sejam menos vulneráveis eleitoralmente a mudanças na conjuntura econômica do que outros. Na próxima seção, analiso o papel da ideologia do partido governista e em seguida o papel da clareza de responsabilidade.

\section{VOTO ECONÔMICO E IDEOLOGIA}

Em países altamente desiguais como os latino-americanos, candidatos de esquerda tendem a propor programas de governo com forte ênfase em políticas redistributivas. Nas eleições brasileiras de 2002, por exemplo, Luiz Inácio Lula da Silva prometeu implementar o programa “Fome Zero", e nas venezuelanas de 1998 e 2000, Hugo Chávez pregou uma revolução bolivariana de caráter socialista. Exemplos como estes são encontrados em toda a região. Por outro lado, candidatos de direita são mais preocupados em manter o status quo e proteger a propriedade privada. Por isso, tendem a enfatizar em seus discursos questões como a segurança nacional, a manutenção da ordem e o combate ao crime organizado. Assim, Álvaro Uribe prometeu não negociar com a guerrilha comunista das Forças Armadas Revolucionárias da Colômbia (FARC) quando concorreu em 2002 e a Aliança Republicana Naciona- 


\section{Diego Sanches Corrêa}

lista (Arena) salvadorenha, que governou o país por muitos anos após o fim da guerra civil, sempre manteve um discurso marcadamente anticomunista. A distância que separa partidos relevantes de esquerda e de direita nos países latino-americanos tem raízes numa distribuição de renda altamente desigual e num passado recente de ditadura e luta armada. Quando esses partidos vencem eleições e passam a governar, boa parte dos eleitores prestará mais atenção nos avanços de suas agendas políticas do que em mudanças na situação econômica do país, ainda que o desempenho econômico possa continuar sendo um parâmetro de avaliação importante. Grosso modo, um governo de esquerda será chamado a prestar contas sobre suas políticas de combate à pobreza, enquanto os de direita serão avaliados pelo seu desempenho na área da segurança pública. Estas e outras eventuais políticas enfatizadas em discursos de incumbentes com inclinações ideológicas à esquerda e à direita rivalizam com o desempenho econômico na cabeça do eleitor quando este avalia retrospectivamente a atuação do governo.

Diversamente, candidatos mais próximos do centro tendem a enfatizar questões com menor potencial para gerar divisões no eleitorado, como a melhoria do desempenho econômico. Curini (2015) demonstra que, em sistemas multipartidários, os incentivos para realizar campanhas com base em questões consensuais, ou valence issues, aumenta para partidos posicionados ideologicamente entre dois adjacentes, um à esquerda e outro à direita. Para partidos de centro, esta é uma estratégia de diferenciação partidária bastante eficaz. É mais fácil atrair eleitores moderados dos partidos adjacentes com discursos enfatizando questões consensuais do que atrair os mais extremistas com discursos enfatizando questões controversas. Este tipo de estratégia também tem consequências para as expectativas do eleitorado e suas escolhas no dia da eleição.

Se este raciocínio estiver correto, a implicação é que variações em indicadores econômicos afetarão mais o desempenho eleitoral de candidatos governistas de centro do que de direita e de esquerda. Para testar esta hipótese, construí indicadores de ideologia do presidente a partir de um índice criado por Wiesehomeier e Benoit (2009) com base em opiniões de analistas. O índice varia de 0 a 20, sendo que valores baixos indicam partidos ou presidentes de esquerda e valores altos indicam partidos ou presidentes de direita. Os presidentes cujos partidos obtiveram um valor menor que 6,67, ou seja, aqueles posicionados no terço inferior da escala foram classificados como sendo de esquerda e aque- 
les que obtiveram um valor maior que 13,33 foram classificados como de direita. Das 76 eleições que compõem as minhas análises, 9 presidentes são de esquerda, 24 de centro e 43 de direita.

Estimei, então, três modelos de regressão linear, incluindo as variáveis binárias "Presidente de Esquerda" e "Presidente de Direita", além de uma interação de cada uma delas com indicadores econômicos. No primeiro modelo, o indicador de desempenho econômico utilizado é o crescimento do PIB, enquanto no segundo e no terceiro é a inflação, tendo sempre como base de referência o desempenho médio da América Latina. A inclusão dessas interações flexibiliza os modelos e permite que o efeito da economia seja diferente para governos de esquerda ("Presidente de Esquerda" = 1 e "Presidente de Direita" =0), governos de direita ("Presidente de Esquerda" $=0$ e "Presidente de Direita" =1) e governos de centro ("Presidente de Esquerda" $=0$ e "Presidente de Direita" =0). Mais especificamente, sendo a equação do modelo de regressão

$$
Y=\beta_{0}+\beta_{1} I+\beta_{2} E+\beta_{3} D+\beta_{12}\left(I^{*} E\right)+\beta_{13}\left(I^{*} D\right)+\ldots+\varepsilon
$$

em que $Y$ é o desempenho eleitoral, $I$ o indicador econômico, $E$ a variável binária "Presidente de Esquerda", $D$ a variável binária "Presidente de Direita" e $\varepsilon$ o erro estocástico, basta substituirmos $E$ e $D$ por 1 ou 0 e somarmos os coeficientes $\beta$ de forma apropriada para encontrarmos o efeito da economia sobre o desempenho eleitoral de cada tipo de candidato incumbente. Assim, $\beta_{1}$ indica o efeito da economia quando este candidato é de centro, já que $E$ e $D$ são iguais a $0 ; \beta_{1}+\beta_{12}$ indica o efeito quando este candidato é de esquerda, já que $E$ é igual a 1 e $D$ é igual a 0 ; e $\beta_{1}+\beta_{13}$ indica o efeito quando este candidato é de direita, já que $E$ é igual a 0 e $D$ é igual a 1 . Os resultados do modelo são apresentados na Tabela 2. O valor dos coeficientes ajustados " $b$ " e seus respectivos valores-p encontram-se na primeira parte da tabela, enquanto os efeitos marginais da economia no desempenho eleitoral de cada tipo de candidato incumbente estão na parte inferior. Como esses efeitos marginais são calculados com base na soma de coeficientes, os erros-padrões foram recalculados, bem como seus valores- $\mathrm{p}^{9}$.

Os resultados do modelo são dignos de nota. O crescimento do PIB e a inflação só afetaram significativamente o desempenho eleitoral de governos de centro. Para cada ponto percentual de crescimento do PIB acima da média latino-americana, o candidato governista de centro ganhou 1,55 ponto percentual de votos válidos relativamente à eleição 
Tabela 2

Voto Econômico e Ideologia

\begin{tabular}{lcccccc}
\hline & \multicolumn{2}{c}{$\begin{array}{c}\text { Crescimento } \\
\text { do PIB }\end{array}$} & Inflação & \multicolumn{2}{c}{$\begin{array}{c}\text { Inflação } \\
\text { Variável }\end{array}$} \\
\cline { 2 - 7 } & $\mathbf{b}$ & $\mathbf{p}$ & $\mathbf{b}$ & $\mathbf{p}$ & $\mathbf{b}$ & $\mathbf{p}$ \\
\hline Economia comparada & 1,55 & 0,00 & $-0,07$ & 0,05 & $-0,10$ & 0,10 \\
Presidente de esquerda & 0,05 & 0,33 & 0,06 & 0,29 & -0.16 & 0.37 \\
Presidente de direita & $-0,01$ & 0,67 & $-0,01$ & 0,83 & $-0,01$ & 0,95 \\
Economia comparada * esquerda & $-0,79$ & 0,57 & 0,30 & 0,13 & NA & NA \\
Economia comparada * direita & $-1,23$ & 0,28 & 0,06 & 0,27 & 0,06 & 0,54 \\
Reeleição & 0,12 & 0,01 & 0,11 & 0,01 & 0,17 & 0,06 \\
Voto anterior & $-0,36$ & 0,01 & $-0,44$ & 0,00 & $-0,60$ & 0,06 \\
Intercepto & 0,05 & 0,43 & 0,08 & 0,28 & 0,10 & 0,59 \\
\hline N & 76 & & 76 & & 22 & \\
$\mathrm{R}^{2}$ ajustado & 0,25 & & 0,21 & & 0,35 & \\
\hline Efeito Marginal da Economia & & & & & & \\
\hline Presidente de centro (N=24) & 1,55 & 0,00 & $-0,07$ & 0,05 & $-0,10$ & 0,08 \\
Presidente de esquerda (N=9) & 0,76 & 0,56 & 0,22 & 0,25 & NA & NA \\
Presidente de direita (N=43) & 0,32 & 0,75 & $-0,02$ & 0,57 & $-0,04$ & 0,52 \\
\hline
\end{tabular}

Fonte: Banco de dados "CCT" (disponível em www.sites.google.com/site/diegosanchescorrea/). Nota: Só há um presidente de esquerda no período 1990-1995: Rodrigo Borja, da Izquierda Democrática no Equador.

anterior. O efeito marginal para os outros dois tipos de candidatos governistas são menores do que a metade deste valor e estatisticamente insignificante. Além disto, uma inflação acima da média latino-americana afetou negativamente a performance de candidatos governistas de centro, mesmo quando todo o período de análise é considerado. A interpretação deste efeito marginal é dificultada pelo fato de a variável ter sido transformada em logaritmo e pela considerável diferença entre as taxas inflacionárias dos anos 1990 e as atuais ${ }^{10}$. Para nós, basta notar que o sinal é negativo e o valor-p indica significância estatística ao nível de 0,05 . Quando a amostra é restrita às eleições que ocorreram entre 1990 e 1995 (modelo 3), o efeito da inflação cresce, bem como o R ${ }^{2}$ ajustado. $\mathrm{O}$ fato de a performance eleitoral de candidatos governistas de centro ser afetada pelos dois indicadores econômicos atesta a sua vulnerabilidade a flutuações econômicas. Por outro lado, a insignificância estatística dos efeitos marginais sobre o desempenho eleitoral dos outros dois tipos de candidatos governistas sugere que questões não econômicas rivalizam com as econômicas na cabeça do eleitor, 
quando este é chamado a avaliá-los retrospectivamente no dia da eleição.

\section{VOTO ECONÔMICO E CLAREZA DE RESPONSABILIDADE}

Uma condição necessária para que presidentes sejam punidos ou recompensados nas urnas pelo desempenho da economia durante seus mandatos é que os eleitores lhes atribuam responsabilidade. Quando partidos aliados e a oposição têm maior influência na condução da política econômica, o presidente pode culpar esses atores em caso de fraco desempenho e esses atores podem reivindicar créditos quando a economia vai bem. Isto confundiria o eleitor no momento de avaliar o governo e geraria dúvidas sobre qual partido punir ou recompensar com o seu voto no dia da eleição. Este tipo de influência contextual da "clareza de responsabilidade" foi descrita e demonstrada por Powell Jr. e Whitten (1993). Os autores utilizaram diversos indicadores de influência de partidos aliados e da oposição sobre a formulação de políticas públicas e encontraram fortes evidências de que condicionam a validade da hipótese do voto econômico. Assim, chefes de governo são chamados a prestar contas sobre o desempenho da economia no dia da eleição apenas quando não dividem funções governamentais com partidos aliados e quando não dependem da cooperação da oposição para governar.

Como apontado no início deste artigo, o problema da análise de Powell Jr. e Whitten é que ela se limitou a países desenvolvidos, quase todos regidos por sistemas parlamentaristas (os Estados Unidos são a única exceção). Estudos posteriores demonstraram que a "clareza de responsabilidade" não afeta a relação de accountability existente entre eleitores e chefe de governo em sistemas presidencialistas, já que o presidente é eleito diretamente pelo povo para um mandato fixo (Hellwig e Samuels, 2008; Samuels, 2004). Segundo estes estudos, as dificuldades do eleitor não estariam na atribuição de responsabilidade pelo desempenho governamental, mas na habilidade de utilizar o voto para agir com base nesta atribuição. Mais especificamente, quando as eleições presidenciais e legislativas são concomitantes, os eleitores são estimulados a focar sua avaliação na performance governamental global e a responsabilizar ambos os poderes por ela. A não concomitância, por outro lado, os estimularia a focar em atributos pessoais na eleição presidencial e questões locais nas eleições legislativas. Consequentemente, uma forte associação entre a economia e o desempenho eleitoral de 


\section{Diego Sanches Corrêa}

candidatos governistas deveria ser encontrada apenas quando a eleição presidencial ocorre concomitantemente à legislativa, o que foi confirmado pelas análises de Hellwig e Samuels (2008).

Para testar esta hipótese, dividi as eleições presidenciais que compõem o banco de dados em concomitantes (63 eleições) e não concomitantes (13 eleições $)^{11}$. Em seguida, reestimei os modelos 2 e 3 apresentados na Tabela 1 para cada uma dessas subamostras. Rigorosamente, esses modelos servem para testar a robustez daqueles demonstrados na Tabela 1 do artigo de Samuels (2004:429), pois seguem a mesma abordagem metodológica com um banco de dados e indicadores econômicos diferentes. Os resultados são apresentados na Tabela 3 e confirmam a hipótese do autor: os modelos para eleições concomitantes são muito semelhantes aos estimados para toda a amostra, enquanto para as não concomitantes os coeficientes são sempre estatisticamente insignificantes. É preciso salientar, entretanto, que eleições não concomitantes correspondem a $17 \%$ dos casos e a $28 \%$ dos países analisados. A maior parte delas ocorreram na Colômbia, onde eleições presidenciais e legislativas, apesar de não serem concomitantes, são realizadas sempre dentro de um intervalo de tempo muito curto (cerca de um mês e meio). Finalmente, note que o $\mathrm{R}^{2}$ ajustado dos modelos para essas eleições são negativos, sugerindo que o baixo número de casos os tornam bastante problemáticos e pouco confiáveis. Qualquer conclusão final com base nesses resultados seria, portanto, imprudente.

Tabela 3

Voto Econômico e Ciclo Eleitoral

\begin{tabular}{|c|c|c|c|c|c|c|c|c|}
\hline \multirow[b]{3}{*}{ Variável } & \multicolumn{4}{|c|}{$\begin{array}{c}\text { Eleições } \\
\text { Concomitantes }\end{array}$} & \multicolumn{4}{|c|}{$\begin{array}{c}\text { Eleições Não } \\
\text { Concomitantes }\end{array}$} \\
\hline & \multicolumn{2}{|c|}{ Modelo 1} & \multicolumn{2}{|c|}{ Modelo 2} & \multicolumn{2}{|c|}{ Modelo 3} & \multicolumn{2}{|c|}{ Modelo 4} \\
\hline & $\mathbf{b}$ & $\mathrm{p}$ & $\mathbf{b}$ & $\mathrm{p}$ & $\mathbf{b}$ & $\mathrm{p}$ & $\mathbf{b}$ & $\mathrm{p}$ \\
\hline Crescimento do PIB comparado & 1,38 & 0,00 & & & $-0,59$ & 0,65 & & \\
\hline Log da inflação comparada & & & $-0,02$ & 0,35 & & & $-0,02$ & 0,84 \\
\hline Reeleição & 0,16 & 0,00 & 0,17 & 0,00 & 0,00 & 0,99 & 0,01 & 0,94 \\
\hline Voto anterior & $-0,41$ & 0,00 & $-0,49$ & 0,00 & 0,43 & 0,37 & 0,44 & 0,36 \\
\hline Intercepto & 0,06 & 0,32 & 0,09 & 0,15 & $-0,28$ & 0,27 & $-0,31$ & 0,25 \\
\hline $\mathrm{N}$ & 63 & & 63 & & 13 & & 13 & \\
\hline$R^{2}$ ajustado & 0,35 & & 0,26 & & $-0,18$ & & $-0,21$ & \\
\hline
\end{tabular}

Fonte: Banco de dados “CCT" (disponível em www.sites.google.com/site/diegosanchescorrea/). 
Para refutar a hipótese de que a clareza de responsabilidade condicionaria os efeitos da economia sobre resultados eleitorais em sistemas presidencialistas, Hellwig e Samuels dividiram uma amostra de 69 eleições presidenciais em duas categorias: uma composta por casos de governo unipartidário de maioria e outra composta pelos demais casos. Mostraram, então, que os efeitos da economia sobre o desempenho eleitoral do candidato governista era semelhante nas duas subamostras (Hellwig e Samuels, 2008:76). No início deste artigo argumentei que há boas razões para se acreditar que a hipótese da clareza de responsabilidade também poderia ser válida para países presidencialistas, contrariamente aos achados desses autores. Para testá-la, dividi a amostra em três, não duas, categorias: uma indicando governos unipartidários de maioria (21 casos); outra, governos de coalizão de maioria (21 casos); e uma terceira indicando governos de minoria (34 casos). A primeira dessas categorias seria caracterizada pela mais alta clareza de responsabilidade; presidentes incluídos na segunda categoria dependeriam apenas da cooperação de partidos aliados para governar; e presidentes incluídos na terceira dependeriam da cooperação da oposição. São, portanto, três contextos políticos nitidamente distintos. Estas categorias foram construídas com base no resultado da mais recente eleição legislativa ocorrida antes da atual eleição presidencial. Para se definir os partidos que compunham o governo no momento da eleição presidencial, verifiquei o partido a que pertencia cada um dos ministros de acordo com o Keesing's World News Archives e diversas edições do Political Handbook of the World.

Os modelos apresentados na Tabela 4 foram estimados de forma análoga àqueles da Tabela 2, mas as variáveis contextuais deixam de ser indicadores de ideologia para serem indicadores de status do governo. Novamente, interações desses indicadores com variáveis econômicas foram incluídas, o que nos permite analisar o impacto da economia em cada um dos três tipos possíveis de contexto político.

Os resultados são inequívocos. A economia só afeta o desempenho eleitoral de candidatos presidenciais governistas quando o governo é unipartidário de maioria. Para cada ponto percentual de crescimento econômico acima da média latino-americana, candidatos governistas de partidos que governaram sós e com maioria ganharam 1,6 ponto percentual de votos válidos. Naturalmente, o inverso é também verdadeiro: crescer pouco custou uma quantidade substancial de votos para esses presidentes. $\mathrm{O}$ efeito marginal da economia também tem sinal 
Tabela 4

Voto Econômico e Clareza de Responsabilidade

\begin{tabular}{lccccccc}
\hline & \multicolumn{3}{c}{$\begin{array}{c}\text { Crescimento } \\
\text { do PIB }\end{array}$} & \multicolumn{2}{c}{ Inflação } & \multicolumn{3}{c}{$\begin{array}{c}\text { Inflação } \\
(<1996)\end{array}$} \\
\cline { 2 - 8 } Variável & $\mathbf{b}$ & $\mathbf{p}$ & $\mathbf{b}$ & $\mathbf{p}$ & $\mathbf{b}$ & $\mathbf{p}$ \\
\hline Economia comparada & 0,92 & 0,23 & 0,00 & 0,97 & $-0,02$ & 0,71 \\
Governo unipartidário de maioria & 0,02 & 0,53 & 0,02 & 0,68 & 0,06 & 0,54 \\
Governo de coalizão de maioria & 0,02 & 0,55 & 0,00 & 0,98 & 0,17 & 0,48 \\
Economia comparada * unipartidário de maioria & 0,67 & 0,51 & $-0,05$ & 0,32 & $-0,09$ & 0,23 \\
Economia comparada * coalizão de maioria & 0,00 & 0,99 & $-0,06$ & 0,39 & $-0,03$ & 0,89 \\
Reeleição & 0,11 & 0,01 & 0,14 & 0,00 & 0,25 & 0,01 \\
Voto anterior & $-0,36$ & 0,01 & $-0,41$ & 0,00 & $-0,44$ & 0,08 \\
Intercepto & 0,04 & 0,58 & 0,06 & 0,38 & $-0,07$ & 0,53 \\
\hline $\mathrm{N}$ & 76 & & 76 & & 22 & \\
$\mathrm{R}^{2}$ ajustado & 0,22 & & 0,16 & & 0,54 & \\
\hline
\end{tabular}

Efeito Marginal da Economia

\begin{tabular}{lllllll}
\hline Governo de minoria (N=35) & 0,92 & 0,23 & 0,00 & 0,97 & $-0,02$ & 0,70 \\
Governo unipartidário de maioria (N=20) & 1,59 & 0,02 & $-0,05$ & 0,17 & $-0,11$ & 0,01 \\
Governo de coalizão de maioria (N=21) & 0,91 & 0,34 & $-0,06$ & 0,32 & $-0,05$ & 0,82 \\
\hline
\end{tabular}

Fonte: Banco de dados "CCT" (disponível em www.sites.google.com/site/diegosanchescorrea/). Nota: Se indicadores econômicos do ano eleitoral são utilizados para eleições que ocorreram no segundo semestre do ano, o efeito para governos de minoria no modelo 1 torna-se estatisticamente significante ao nível de 0,1, mas mantém-se 34\% menor em magnitude em relação a governos unipartidários de maioria.

positivo para os outros contextos políticos, mas ele é $40 \%$ menor em magnitude e estatisticamente insignificante. Presidentes que governam em coalizão ou com minoria são eleitoralmente menos vulneráveis a variações da conjuntura econômica, semelhantemente ao que Powell Jr. e Whitten encontraram para países parlamentaristas.

Os modelos para inflação são também bastante sugestivos. No modelo 2, que inclui todos os casos da amostra, a magnitude dos efeitos da variação de preços sobre a performance eleitoral de candidatos governistas é a mesma para governos de maioria, sejam eles unipartidários ou de coalizão. Nenhum deles é estatisticamente significante, no entanto, embora o efeito para governos unipartidários esteja mais próximo de o ser. Quando restringimos a amostra para as eleições que ocorreram entre 1990 e 1995, o efeito para governos unipartidários de maioria dobra e adquire significância estatística ao nível de 0,05 , enquanto o efeito para governos de coalizão de maioria permanece insignificante. Note 
também o impressionante aumento do $\mathrm{R}^{2}$ ajustado, sugerindo que os eleitores realmente deram um peso muito alto à inflação quando foram às urnas naquele período. Manter a inflação abaixo da média latino-americana beneficiou muito os presidentes que governaram sós e com maioria, da mesma forma que o descontrole dos preços arruinou seus prognósticos eleitorais.

A categoria de governos unipartidários de maioria não coincide com a categoria de presidentes de centro. Dos 21 casos de governos unipartidários de maioria, 3 são de esquerda, 10 de direita e 8 de centro. Dos 24 casos de governos de centro, 10 se referem a governos de minoria, 8 a governos unipartidários de maioria e 6 a governos de coalizão de maioria. Isto é, os efeitos do status do governo e da ideologia do presidente explicam de forma independente a ocorrência do voto econômico na América Latina: candidatos governistas de centro tiveram seu desempenho eleitoral afetado pela economia, independentemente do contexto político em que governaram e a economia afetou o desempenho de governos unipartidários de maioria independentemente da ideologia do chefe de governo ${ }^{12}$.

\section{CONCLUSÕES}

Cidadãos latino-americanos têm vivenciado períodos de crise inflacionária e recessão econômica com muito mais frequência que cidadãos de países-membros da OCDE. Por esta razão, a economia é frequentemente apontada como um forte determinante de resultados eleitorais na região (Singer, 2013). A maior parte dos estudos comparados do voto econômico publicados nas últimas décadas buscou identificar fatores contextuais que interferem na magnitude e significância desta associação. Este artigo está inserido nesta mesma agenda de pesquisa e contribui com o debate do voto econômico na América Latina de duas maneiras. Primeiro, a ideologia do presidente afeta as expectativas dos eleitores e os parâmetros que estes utilizam para avaliar retrospectivamente a atuação do governo. Uma associação forte e significativa entre indicadores econômicos e o desempenho eleitoral de candidatos à reeleição só ocorre quando o governo é de centro. Segundo, a clareza de responsabilidade também tem efeitos sobre esta relação entre economia e eleições, semelhante ao que Powell Jr. e Whitten (1993) encontraram para países parlamentaristas e contrariamente aos achados de Samuels (2004) e Hellwig e Samuels (2008), que focaram países presidencialistas. 


\section{Diego Sanches Corrêa}

No que tange à influência da ideologia, este artigo sugere que ela está enraizada em dois fatores: um referente a incentivos eleitorais por parte de candidatos presidenciais e outro referente aos parâmetros de avaliação do governo utilizados pelos eleitores. Como demonstrou Curini (2015), a ideologia dos partidos políticos afeta suas estratégias eleitorais. O incentivo para se realizar campanhas e propor programas de governo com ênfase em questões consensuais, como o crescimento econômico, aumenta com a proximidade ideológica de outros partidos. Para partidos de centro, é mais eficaz buscar convencer eleitores moderados de sua competência administrativa do que construir discursos enfatizando questões tradicionalmente dominadas por partidos de esquerda e de direita. Analogamente, partidos mais próximos dos extremos ideológicos têm incentivos para garantir o apoio de eleitores mais radicais com base em propostas mais controversas. O conteúdo da campanha e das propostas de governo afeta as expectativas dos eleitores sobre as realizações do presidente durante o mandato e, consequentemente, os parâmetros que utilizam para avaliar sua atuação. Se partidos de centro querem fazer crer que possuem mais competência para estimular a economia, o que é algo desejado por toda a população, então flutuações em indicadores econômicos deverão afetar mais fortemente seus prospectos eleitorais. Da mesma maneira, se partidos de esquerda argumentam recorrentemente que a desigualdade social é o principal problema da nação, enquanto os de direita afirmam que é a criminalidade, então a economia terá um peso relativamente menor, ainda que não irrelevante, nos seus prognósticos.

No que diz respeito ao papel da clareza de responsabilidade, os resultados apresentados aqui sugerem que as relações de accountability eleitoral em sistemas parlamentaristas e presidencialistas são mais parecidas do que sugerido pelos estudos mais recentes. Os mecanismos que, segundo Powell Jr. e Whitten (1993), condicionam a capacidade dos eleitores de atribuir responsabilidades e punir ou recompensar partidos governistas em sistemas parlamentaristas parecem ser também importantes nos sistemas presidencialistas latino-americanos, o que contraria os argumentos de Samuels (2004) e Hellwig e Samuels (2008). A necessidade de formar coalizões de governo e de buscar a cooperação da oposição quando o governo não detém maioria na Câmara Legislativa requer barganhas políticas que diminuem a discricionariedade do presidente. Culpar a oposição e dividir responsabilidades com aliados no discurso político é algo racional e, certamente, rotineiro também nas democracias presidencialistas latino-americanas. Isto 
pode confundir o eleitor no momento de avaliar retrospectivamente a atuação do governo e diminuir o impacto de flutuações econômicas no desempenho eleitoral de candidatos presidenciais governistas. Assim, como demonstrado neste artigo, uma forte associação entre economia e resultados eleitorais só é observada quando o governo é unipartidário de maioria.

(Recebido para publicação em agosto de 2014) (Aprovado para publicação em novembro de 2014) 


\section{Diego Sanches Corrêa}

\section{NOTAS}

1. Não há, na língua portuguesa, uma tradução fiel ao significado que o conceito de accountability tem na língua inglesa. Algumas das traduções mais frequentes na literatura brasileira são "responsabilização" e "prestação de contas", mas a primeira possui um escopo muito mais amplo e genérico e a segunda falha por sinalizar apenas parcialmente o significado do termo original. Não basta que o agente preste contas; é preciso também que o mandatário (principal) seja capaz de julgá-lo e sancioná-lo. Em razão disto, optei por manter a palavra em inglês ao longo deste artigo.

2. O autor defende a tese de que o conceito de accountability não tem relevância em análises de sistemas políticos proporcionalistas como a literatura quer fazer crer e analisa criticamente a produção de uma agenda de pesquisa importante na política comparada, dentro da qual este artigo se insere. Se há algum ponto de coerência entre os argumentos aqui apresentados e a crítica elaborada por Melo (2007), provavelmente ele se encontra no fato de que minhas análises se restringem a eleições presidenciais, todas elas majoritárias, nas quais o conceito de accountability teria uma importância teórica e normativa maior, como implica o próprio argumento do autor.

3. Uma pesquisa de opinião realizada pelo Wall Street Journal logo após o governo fechar as portas mostrou que a popularidade do Partido Republicano havia caído para o menor índice em 25 anos e que a do presidente Obama permanecia no mesmo nível das pesquisas anteriores. Os resultados estão disponíveis em $<\mathrm{http}$ ://online.wsj. com/public/resources/documents/WSJNBCpoll10072013.pdf >. Acessado em julho de 2014.

4. Este banco de dados tem o nome de "CCT" e pode ser acessado em http:/ / www.sites.google.com/site/diegosanchescorrea/.

5. Todas estas informações foram extraídas de fontes oficiais, como o Tribunal Superior Eleitoral (TSE) para o caso do Brasil.

6. O candidato que venceu a eleição anterior não é o atual presidente em casos de impeachment ou morte. Por exemplo, o partido governista na eleição brasileira de 1994 é o Partido da Reconstrução Nacional (PRN), partido do candidato eleito em 1989, e não o Partido do Movimento Democrático Brasileiro (PMDB), partido do vice-presidente que tomou posse por meios não eleitorais após o processo de impeachment.

7. São elas as eleições da Colômbia, de 2002; Equador, de 1996 e 2002; Guatemala, de 1995; Nicarágua, de 1996; Peru, de 2001 e 2006; e Venezuela, de 1998.

8. É comum na literatura a utilização de dados do ano anterior para eleições que ocorreram no primeiro semestre e do ano eleitoral para aquelas que ocorreram no segundo. Reestimei todos os modelos apresentados ao longo deste artigo seguindo esta abordagem e os resultados e conclusões são substantivamente os mesmos, com uma única exceção indicada na Tabela 4. Optei por manter os resultados estimados com dados econômicos do ano anterior, pois os do ano eleitoral são divulgados somente no ano seguinte, sendo assim desconhecidos pelos eleitores quando estes vão às urnas.

9. A fórmula do erro-padrão do efeito marginal da economia sobre o desempenho eleitoral de candidatos incumbentes de esquerda é: $\sigma=\sqrt{\operatorname{var}\left(\beta_{1}\right)+E^{2} \operatorname{var}\left(\beta_{12}\right)+2 E \operatorname{cov}\left(\beta_{1} \beta_{12}\right)}$, em que "var" é variância e "cov" covariância. Para os de direita, a fórmula é análoga. A partir deste erro-padrão, obtem-se um 
novo valor-p através de um teste-z. Note que é possível que o efeito marginal da economia sobre o desempenho de candidatos incumbentes de esquerda $\beta_{1}+\beta_{12}$ ou de direita $\beta_{1}+\beta_{13}$ seja significante, ainda que nenhum dos parâmetros do modelo o seja. Para uma descrição de como estimar efeitos marginais de variáveis em modelos com interações multiplicativas, ver Bambor, Clark e Golder (2006).

10. O modelo prediz que para cada unidade adicional da diferença entre o log da inflação nacional e o log da inflação latino-americana, o candidato governista perde 0,07 ponto percentual de votos válidos. Quando a inflação nacional é $172 \%$ maior que a média latino-americana (por exemplo, quando a inflação nacional é 13,6\% e a latino-americana é $5 \%$ ), a diferença entre os logs desses valores é igual ao log de $e$, que é igual a 1. Neste caso, o candidato governista perderia 0,07 ponto percentual de votos relativamente a se a inflação nacional tivesse sido igual à média latino-americana. Este valor pode parecer baixo para os padrões atuais, mas certamente não o foi para os padrões do início dos anos 1990, quando alguns países tinham taxas muitas vezes superiores, e outros muitas vezes inferiores, à média latino-americana.

11. São eleições não concomitantes: a chilena, de 1999, todas as cinco colombianas, as quatro dominicanas, entre 1996 e 2008, e as salvadorenhas, de 1999 e 2004 e a venezuelana de 2006. A eleição colombiana de 2002 e a venezuelana de 1998 também não são concomitantes, mas foram excluídas da análise por não terem sido disputadas por candidatos governistas.

12. Idealmente, a influência da ideologia e da clareza de responsabilidade deveriam ter sido analisadas num mesmo modelo estatístico, possivelmente com a inclusão de interações com elas e delas com indicadores econômicos. No entanto, este tipo de abordagem tornaria o modelo demasiadamente complexo para o baixo número de casos incluídos na amostra, comprometendo qualquer tipo de inferência. Foi esta a razão que me levou a analisar a influência de cada um desses fatores contextuais em separado. 


\section{Diego Sanches Corrêa}

\section{REFERÊNCIAS BIBLIOGRÁFICAS}

ANDERSON, Christopher J. (1995), Blaming the Government: Citizens and the Economy in Five European Democracies. Armonk, NY, M. E. Sharpe.

. (2007), "The End of Economic Voting? Contingency Dilemmas and the Limits of Democratic Accountability". Annual Review of Political Science, vol. 10, no 1, pp. 271-296.

BRAMBOR, Thomas; CLARK, William R. e GOLDER, Matt. (2006), “Understanding Interaction Models: Improving Empirical Analyses". Political Analysis, vol. 14, no 1, pp. 63-82.

CHEIBUB, José Antonio e PRZEWORSKI, Adam. (1999), "Democracy, Elections, and Accountability for Economic Outcomes", in A. Przeworski; S. C. Stokes e B. Manin (orgs.), Democracy, Accountability, and Representation. New York, Cambridge University Press, pp. 222-250.

CURINI, Luigi. (2015), "The Conditional Ideological Inducement to Campaign on Character Valence Issues in Multiparty Systems: The Case of Corruption". Comparative Political Studies, vol. 48, no 2, pp. 168-192.

DAHL, Robert A. (1973), Polyarchy: Participation and Opposition. New Haven, Yale University Press.

ECHEGARAY, Fabián. (2005), Economic Crises and Electoral Responses in Latin America. Lanham, University Press of America.

HELLWIG, Timothy e SAMUELS, David. (2008), "Electoral Accountability and the Variety of Democratic Regimes". British Journal of Political Science, vol. 38, no 1, pp. 65-90.

LEWIS-BECK, Michael S. e STEGMAIER, Mary. (2008), "The Economic Vote in Transitional Democracies". Journal of Elections, Public Opinion and Parties, vol. 18, no 3, pp. 303-323.

MANIN, Bernard; PRZEWORSKI, Adam e STOKES, Susan C. (1999), "Elections and Representation", in A. Przeworski; S. C. Stokes e B. Manin (orgs.), Democracy, Accountability, and Representation. New York, Cambridge University Press, pp. 29-54.

MELO, Marcus André. (2007), “O Viés Majoritário na Política Comparada: Responsabilização, Desenho Institucional e Qualidade Democrática". Revista Brasileira de Ciências Sociais, vol. 22, o 63, pp. 11-29.

MORENO, Erika; CRISP, Brian e SHUGART, Matthew S. (2003), “The Accountability Deficit in Latin America", in S. Mainwaring e C. Welna (orgs.), Democratic Accountability in Latin America. Oxford, UK, Oxford University Press, pp. 79-131.

NANNESTAD, Peter e PALDAM, Martin. (2002), "The Cost of Ruling", in H. Dorussen e M. Taylor (orgs.), Economic Voting. London/New York, Routledge, pp. 17-44.

POWELL JR., G. Bingham e WHITTEN, Guy D. (1993), “A Cross-National Analysis of Economic Voting: Taking Account of the Political Context". American Journal of Political Science, vol. 37, no 2, pp. 391-414. 
REMMER, Karen L. (1991), “The Political Impact of Economic Crisis in Latin America in the 1980". The American Political Science Review, vol. 85, no 3, pp. 777-800.

. (2003), "Elections and Economics in Latin America", in V. Wise e R. Roett (orgs.), Post-Stabilization Politics in Latin America: Competition, Transition, Collapse. Washington, DC, Brookings Institution Press, pp. 31-55.

SAMUELS, David. (2004), "Presidentialism and Accountability for the Economy in Comparative Perspective". American Political Science Review, vol. 98, no 3, pp. 425-436.

SINGER, Matthew M. (2013), "Economic Voting in an Era of Non-Crisis: The Changing Electoral Agenda in Latin America, 1982-2010". Comparative Politics, vol. 45, no 2, pp. 169-185.

WIESEHOMEIER, Nina e BENOIT, Kenneth. (2009), "Presidents, Parties, and Policy Competition". The Journal of Politics, vol. 71, no 4, pp. 1435-1447. 


\section{Diego Sanches Corrêa}

\section{RESUMO}

Economia, Ideologia e Eleições na América Latina

Este artigo analisa o impacto da economia nas eleições presidenciais latino-americanas ocorridas entre 1990 e 2010. Os resultados aqui apresentados demonstram que a ideologia do presidente e o contexto político condicionam este impacto e que, portanto, a natureza da relação de accountability entre eleitores e presidentes varia entre países e administrações presidenciais. Em primeiro lugar, a economia só afetou o desempenho eleitoral de candidatos governistas de centro, sugerindo que os eleitores dão mais peso a áreas não econômicas quando avaliam a administração de presidentes de direita e de esquerda. Em segundo, a economia só afetou o desempenho eleitoral de candidatos governistas em contextos de maioria e partido único, o que indica que os eleitores latino-americanos não atribuem responsabilidade aos presidentes pela performance econômica quando estes dependem de aliados ou da cooperação da oposição para governar.

Palavras-chave: voto econômico; América Latina; responsabilidade; ideologia; presidencialismo

\section{ABSTRACT \\ Economy, Ideology and Elections in Latin America}

This article analyzes the impact of the economy on Latin American presidential elections between 1990 and 2010. The results presented here demonstrate that the incumbent's ideology and the political context affect this impact and that, therefore, the nature of the accountability relationship between voters and presidents varies across countries and presidential administrations. Firstly, the economy only affected the electoral performance of centrist incumbents, suggesting that voters give more importance to non-economic issues when evaluating the administration of right and left-wing presidents. Secondly, the economy only affected the electoral performance of incumbent candidates in single-party majority, which indicates that Latin American voters do not hold presidents accountable for economic performance when they depend on allies or the cooperation of the opposition to govern.

Keywords: economic vote; Latin America; accountability; ideology; presidentialism 


\section{RÉSUMÉ}

Économie, Idéologie et Élections en Amérique Latine

Cet article analyse l'impact de l'économie sur les élections présidentielles latino-américaines de 1990 à 2010. Les résultats ici présentés démontrent que l'idéologie du président et le contexte politique conditionnent cet impact et que la nature de la relation d'accountability entre électeurs et présidents varie donc selon les pays et les administrations présidentielles. En premier lieu, l'économie n'a affecté les performances électorales que de sortants centristes, suggérant ainsi que les électeurs accordent plus d'importance aux questions non économiques lorsqu'ils évaluent le mandat de présidents de droite ou de gauche. En second lieu, l'économie n'a eu d'influence électorale que dans le cas de sortants insérés dans des contextes de majorité absolue et de parti dominant, ce qui indique que les électeurs latino-américains n'attribuent pas aux présidents la responsabilité des performances économiques lorsque ceux-ci dépendent d'alliances ou de la coopération de l'opposition pour gouverner.

Mots-clés: vote économique; Amérique Latine; responsabilité; idéologie; présidentialisme

\section{RESUMEN}

\section{Economía, Ideología y Elecciones en América Latina}

Este artículo analiza el impacto de la economía en las elecciones presidenciales latinoamericanas ocurridas entre 1990 y 2010. Los resultados presentados demuestran que la ideología del presidente en funciones y el contexto político condicionan este impacto y que, por lo tanto, la naturaleza de la relación de accountability entre electores y presidente cambia entre países y administraciones presidenciales. En primer lugar, la economía sólo afectó el desempeño electoral de presidentes de centro, lo que sugiere que los electores dan más peso a áreas no económicas cuando valoran las administraciones de presidentes de derecha y de izquierda. En segundo, la economía sólo afectó el desempeño electoral de aquellos presidentes en contextos de mayoría y de partido único, lo que indica que los electores latinoamericanos no atribuyen responsabilidad a los presidentes por la performance económica cuando éstos dependen de aliados o de la cooperación de la oposición para gobernar.

Palabras clave: voto económico; América Latina; responsabilidad; ideología; presidencialismo 


\section{$B R E ́ S I L(S)$}

ISSN 2257-0543

REVISTA SEMESTRAL

$n^{\circ} 7$ - Les mobilisations de juin 2013

Maio de 2015

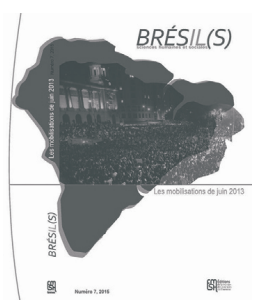

\section{Dossier « Les mobilisations de juin 2013 »}

Breno Bringel et Geoffrey Pleyers

Les mobilisations de 2013 au Brésil : vers une recon guration de la contestation

Marco Antonio Perruso et Viviane Becker Narvaes

Les Journées de(puis) juin 2013

Lucia Rabello de Castro et Conceição Firmina Seixas Silva

L'action politique des jeunes étudiants au Brésil aujourd'hui : le présage de la $n$ d'une époque

Cristiana Losekann

Dynamiques et effets des manifestations brésiliennes de 2013 : le cas de la ville de Vitória

Francisco Mata Machado Tavares et João Henrique Ribeiro Roriz

Avant juin, les rues de mai. Étude de cas sur les manifestations en faveur de la mobilité urbaine dans la ville de Goiânia

Yves Cohen et Marco Aurélio Santana

Du Brésil au monde et retour : mouvements sociaux localisés et en résonance

\section{Varia}

Sandra Guardini Teixeira Vasconcelos

Déplacements, décentrages : le roman en transit

Luisa Farah Schwartzman et Simon Schwartzman

Migrations des personnes hautement quali ées au Brésil. De l'isolement l'insertion internationale

Flávio dos Santos Gomes et Maria Helena P. T. Machado

Migrations dans l'arrière-pays, formes d'occupation des territoires et quilombos itinérants São Paulo ( VIlle- I e siècles)

Fabio Mallart

Du Statut de l'enfant et de l'adolescent aux « prisons dominées ». Dynamique de fonctionnement du système socio-éducatif d'internement

\section{Brésil(s) existe em versão electrônica : bresils.revues.org}

Números avulsos : $16 €$

\section{Condições de compra}

Particulares: pela internet no "Comptoir des presses" - www.lcdpu.fr ou no site da editora - www.editions-msh.fr Institucionais: + cid@msh-paris.fr ou 2 + 33 (1) 53482095

Assinatura

CRBC - EHESS - 190-198 avenue de France - 75244 Paris cedex 13 - bur. 420 Responsável pelas assinaturas: Dominique Duchanel ( + 33 (1) 49542219 - + bresils-revue@ehess.fr Preço (2 números por ano)

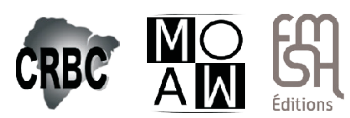
França: individual $29 €$ - institucional $35 €$ Exterior: individual $36 €$ - institucional $40 €$ 